\title{
Effects of high power illuminators on vision through windscreens and driving behavior
}

\author{
Alexander Toet, Johan W.A.M. Alferdinck \\ TNO, Kampweg 5, 3769 DE, Soesterberg, The Netherlands \\ E-mail: \{lex.toet johan.alferdinck\}@tno.nl
}

\begin{abstract}
In this study we investigated the effectiveness of high power illuminators that are intended to be used as warning devices or non-lethal weapons to deny car drivers their view on the outside world through windscreens. The test is based on a measurement of the amount of veiling glare resulting when a high intensity light source hits a windscreen. We measured the veiling glare for new, used and colored windscreens that were either clean or dirty. We found no significant difference between the scatter function for new, used and colored windows. The scatter function for dirty windscreens is a factor 14 larger than for clean windscreens. We also derived a method to assess the impact of the illumination of a windscreen by a high intensity light source on driving behavior. The method is based on the assumption that drivers reduce their speed when veiling glare reduces the detection distance of objects on the road. Estimates of respectively the detection distance for objects on the road and the maximum safe driving speed are directly related to operational requirements, and can therefore be used to assess the operational effectiveness of high intensity light sources as powerful warning devices or non-lethal weapons.
\end{abstract}

Keywords: non-lethal weapons, high power illuminators, lasers, warning signals.

\section{INTRODUCTION}

Laser and other high power illuminators are increasingly deployed as a means to deter and interrogate potentially hostile targets approaching checkpoints or high value targets ${ }^{1-3}$. The current study focuses on the effectiveness of high intensity light sources as non-lethal weapons. The objective of this study was to develop a test protocol for the qualification of high intensity light sources that are intended to be used as warning devices or to deny car drivers their view on the outside world through windscreens.

This paper is structured as follows. In Section 2 we present an overview of the relevant visual effects that occur when a driver is confronted with a high intensity light source at low light conditions. Section 3 describes the materials and method that were used in the study. Section 4 presents the results of the windscreen scatter measurements. In Section 5 the impact of the windscreen scatter on driving behavior is assessed through computational method to. Finally, we present conclusions and recommendations in Section 6.

\section{HIGH INTENSITY LIGHTS, WINDSCREENS AND HUMAN VISION}

\subsection{Visual effects}

Ocular exposure to a high intensity light such as a laser can result in profound losses in vision. These vision losses can be temporary ${ }^{4}$, permanent ${ }^{5}$, or a combination of both, depending on the wavelength, power or energy, and the divergence of the light beam. The effects are typically delineated as reversible (e.g., glare and flash insensitivity or "flash blindness") or irreversible (e.g., retinal tissue damage). In this study we will only consider exposures resulting in reversible effects.

In addition to loss of vision, exposures to high intensity light sources can also produce a range of subjective responses, ranging from distraction and disruption to disorientation and even to incapacitation. The impact of an exposure depends not only on the exposure level, but also on the exposed individual's activity, psychological state, adaptation level and visual task.

\footnotetext{
Technologies for Optical Countermeasures X; and High-Power Lasers 2013: Technology and Systems, edited by David H. Titterton, Mark A. Richardson, Robert J. Grasso, Harro Ackermann, Willy L. Bohn,

Proc. of SPIE Vol. 8898, 88980I - C 2013 SPIE - CCC code: 0277-786X/13/\$18 - doi: 10.1117/12.2028224
} 
So, exposure to high intensity lights can cause temporary visual impairment such as glare or flash blindness. This can seriously degrade the performance of tasks that require vision. Glare is defined as the momentary visual loss that occurs while the light source is on. Flash blindness is a temporary visual loss following a brief exposure to an abrupt increase in the brightness of all or part of the field of view ${ }^{6}$. Flash blindness continues after the termination of the exposure. The temporary visual impairment can be localized (when only a small part of the visual field is illuminated) or global (when the entire visual field is illuminated). During flash blindness virtually nothing is visible in the affected parts of the retina except the afterimages ${ }^{6}$. Depending on the adaptation state of the eye and the exposure level flash blindness may last up to several minutes.

\subsection{Critical illuminance levels}

In contrast to the effects of lasers, the effects of other high intensity lights on human vision in low ambient light conditions have not been sufficiently investigated. As a result there are currently no well-defined threshold illuminance levels corresponding to the different visual interference effects that may occur when a person is confronted with a high intensity light while performing a complex task (e.g., driving a vehicle). The Society of Automotive Engineers (SAE) therefore proposed to adopt the existing laser safety zoning for critical tasks (e.g., flying an airplane) also for other high intensity light sources and to convert the corresponding maximum admissible irradiance exposure levels to values that apply to broadband high intensity lights ${ }^{7}$.

The ANSI Z136.6 standard defines laser irradiance $\left(\mathrm{W} / \mathrm{cm}^{2}\right)$ threshold exposure levels for visual interference at dusk or at night ${ }^{8}$. When applied to broadband high intensity lights, the appropriate corresponding measure is illuminance (lx). The laser irradiance threshold levels corresponding to the different visual interference effects can be converted into illuminance threshold levels through multiplication by the luminous efficacy at the peak photopic response, which is 683 $1 \mathrm{~m} / \mathrm{W}$ at $555 \mathrm{~nm}^{7,9}$. Note that this conversion is based on the assumption that photopic vision applies. The SAE argues that this assumption is reasonable when applied to pilots, because the aviator's eyes are generally not entirely dark adapted at night due to ambient lighting, such as illuminated cockpit gauges and ground lights ${ }^{7}$. The same argument probably holds for driving a vehicle at night. Further studies may be required to assess the validity of this assumption. The resulting relationship between broadband illuminance and laser irradiance is shown in Table 1.

Table 1. Broadband illuminance threshold exposure levels, and corresponding laser irradiance thresholds for different visual effects, as defined by ANSI Z136.6 (American National Standards Institute, 2005, Table 5).

\begin{tabular}{|lcc|}
\hline Visual effect & Irradiance threshold [W/cm $\left.{ }^{2}\right]$ & Illuminance threshold [Ix] \\
\hline Eye damage & $2.5 \times 10^{-3}$ & 17,000 \\
Afterimages, flash blindness & $1 \times 10^{-4}$ & 680 \\
Glare & $5 \times 10^{-6}$ & 34 \\
Startle, distraction & $5 \times 10^{-8}$ & 0.34 \\
\hline
\end{tabular}

\subsection{Contrast reduction by windscreens}

Many different factors affect light transmission through optical transparencies, thereby altering apparent visual contrast. These factors include light scatter, reflections and birefringence. In addition, the plastics used in windscreens can be crazed or pitted by chemical agents such as cleaning fluids, or by impact with particulate matter during driving. There may be pre-existing optical defects, such as mounting stresses, media imperfections and delamination, which can result in distortions or reduced optical clarity.

When the beam of a high intensity light source hits a windscreen the driver may experience severe visual contrast reduction due to veiling glare ${ }^{10}$. When the source is located straight ahead the driver will perceive the glare source in his central visual field and the main source of contrast reduction will be the light scattered internally in his eyes (disability glare). When the laser beam strikes the vehicle sideways, the windscreen may act as a waveguide and may partially absorb the beam. As a result the windscreen will light up, introducing a light veil that will further reduce the visibility of objects both inside and outside the vehicle.

There are many different ways to evaluate the factors that degrade visual performance through optical transparencies ${ }^{10}$. For example, Allen ${ }^{11}$ used target detection and recognition tasks to characterize the degree of veiling glare in vehicle windscreens. More recently, Timmerman ${ }^{12}$ measured the intensity of scattered light at different viewing angles behind an 
automobile windscreen and found that glare recovery time and target detection were adversely affected in the presence of a large amount of scattered light. However, the most common metric to quantify the deleterious effects of a glare source is still the reduction in visibility or contrast of objects seen through a transparency in the presence of scatter.

The appropriate measure for this study is the reduction in contrast of details in a scene viewed through a windshield that is hit by the beam of a high intensity light source. The visual contrast of an object can be defined as

$$
C=\frac{\left|L_{o}-L_{b}\right|}{L_{b}}
$$

where $L_{o}$ represents the luminance of the object (the amount of emitted or reflected radiation, weighted with the eye's sensitivity, per unit area expressed in candela per square meter; $\mathrm{cd} / \mathrm{m}^{2}$ ) and $L_{b}$ is the luminance of the object's background. The incoming high intensity light beam induces a light veil with luminance $L_{v}$. The contrast reduction can then be written as:

$$
C^{\prime}=\frac{\left|\left(L_{o}+L_{v}\right)-\left(L_{b}+L_{v}\right)\right|}{L_{b}+L_{v}}=\frac{\left|L_{o}-L_{b}\right|}{L_{b}+L_{v}}
$$

The following example serves to illustrate the impact of this effect. Let the luminance of an object (e.g. a vehicle) be 20 $\mathrm{cd} / \mathrm{m}^{2}$, and let the luminance of the background (e.g., the surrounding terrain) be $40 \mathrm{~cd} / \mathrm{m}^{2}$. The contrast of the object relative to its local background is then $C=\frac{|20-40|}{40}=0.5$. Suppose the veiling luminance introduced by the high intensity light is $60 \mathrm{~cd} / \mathrm{m}^{2}$. In this situation the contrast of the object and its surround is $C^{\prime}=\frac{|20-40|}{40+60}=0.2$. Hence, visual contrast is reduced by $60 \%$ by the activation of the high intensity light. If the laser reduces the contrast of objects below the visual contrast threshold of the human eye they can no longer be seen. The contrast threshold depends on the background luminance and the perceived size of an object ${ }^{13,14}$ (Figure 1). For small objects at daytime (i.e., for $\mathrm{L}_{b}>10$ $\mathrm{cd} / \mathrm{m}^{2}$ ) the visual contrast threshold of the human eye is about $\mathrm{C}=0.05$.

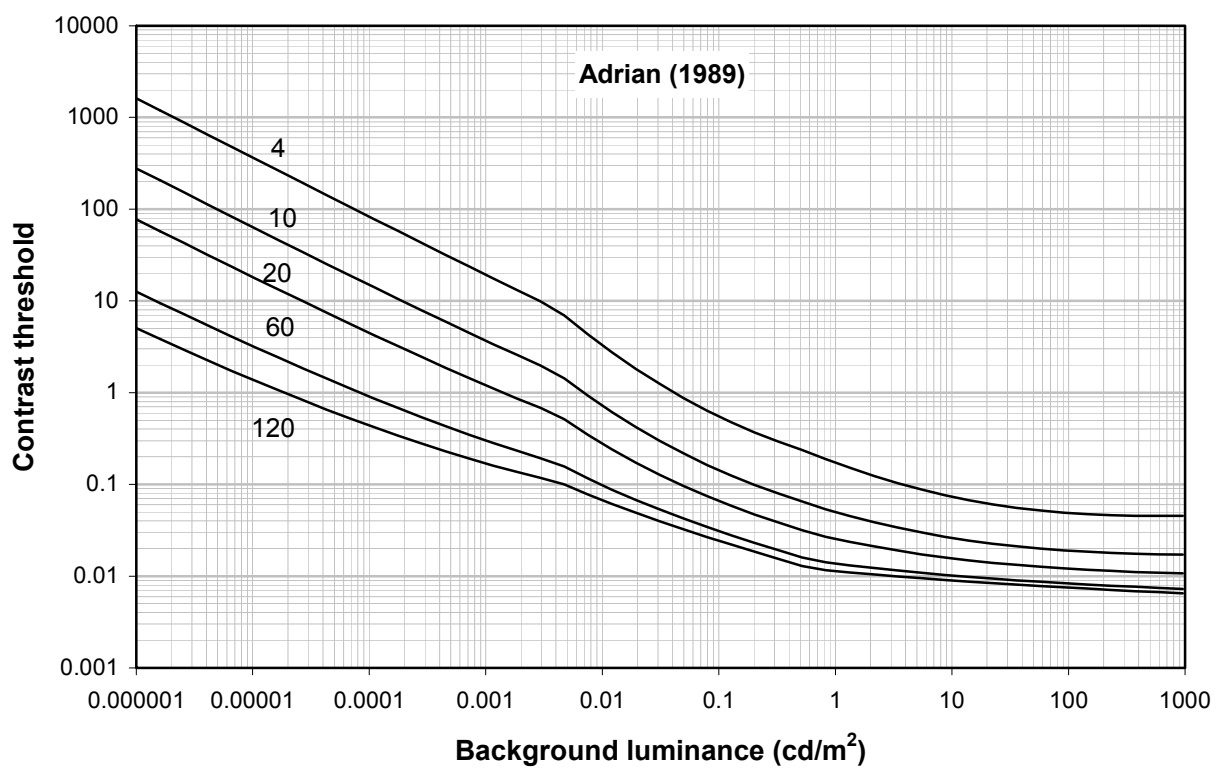

Figure 1. Contrast threshold as a function of background luminance and diameter (in arc minutes) of a circular object, according a visibility model of Adrian ${ }^{13}$ based on data of Backwell ${ }^{14}$. 


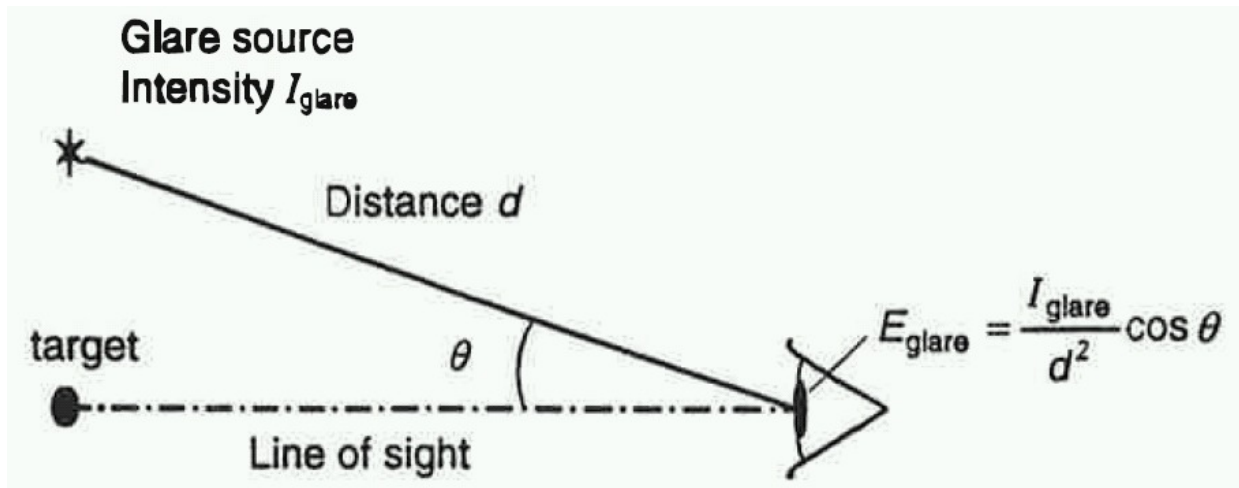

Figure 2. Geometry in glare situations with a point glare source and an observed point target ${ }^{15}$.

\subsection{Disability glare}

Glare that impairs vision is called disability glare. Disability glare is primarily caused by the scattering of light inside the eye due to the imperfect transparency of the optical components of the eye and to a lesser extent by diffuse light passing through the scleral wall or the iris ${ }^{15}$. The scattered light overlays the retinal image, thus reducing visual contrast. This overlaying scattered light distribution is usually described as a veiling luminance. This veiling luminance in the human eye reduces the contrast in the scene in the same manner as the veiling luminance due to the presence of a windscreen. The veiling luminances of respectively the windscreen and the eye can be summed in the calculation of the contrast reduction, and in the calculation of the detection distance of objects in the scene. The veiling luminance $\mathrm{L}_{\mathrm{v}, \mathrm{eye}}$ (in $\mathrm{cd} / \mathrm{m}^{2}$ ) in the eye caused by a point source (Figure 2) can be described by the CIE General Disability Glare Equation ${ }^{15}$ :

$$
L_{v, \text { eye }}=E_{\text {glare }}\left[\frac{10}{\theta^{3}}+\left[\frac{5}{\theta^{2}}+\frac{0.1 p}{\theta}\right] \cdot\left[1+\frac{A^{4}}{62.5}\right]+0.0025 p\right]
$$

where $E_{\text {glare }}$ is the illuminance at the eye (in lx), $\theta$ the glare angle (in degrees), $A$ the age of the observer (in years) and $p$ the pigmentation of the eye, which ranges from 0 for black eyes, via 0.5 for brown eyes to 1 for light eyes and 1.2 for light blue eyes.

\section{MATERIALS AND METHODS}

\subsection{Test overview}

When the beam of a high intensity light source hits a windscreen the driver may experience severe visual contrast reduction due to veiling glare ${ }^{10}$. Veiling glare arises both from light scattered in the eye and light scattered by the windscreen. The amount of veiling glare may depend to a greater or lesser extent on the following factors:

- Colour (green, blue, bronze or white) and coating of the windshield.

- Geometry of the windshield (shape and orientation, depending on vehicle type).

- Condition of the windshield (new or used, with slight imperfections).

- State of the windshield (clean, dirty, water droplets).

- Relative ambience, i.e. the difference in ambient light intensity inside and outside the vehicle.

- Distance of the light source.

- Characteristics of the light source (color, narrow or wide mode, pulsed or continuous mode).

- Angle of engagement (glare angle $\theta$ ).

- Characteristics of the human eye.

- Position of the driver relative to the windscreen and the spot of the light source.

Not all sources of variability have been explored independently. We used a limited set of windscreens (combination of color, geometry, condition and state) and a single light source (given characteristics and distance). Our aim was to determine the difference in light scatter functions for new and used windscreens that were either clean or dirty, for different glare angles. 


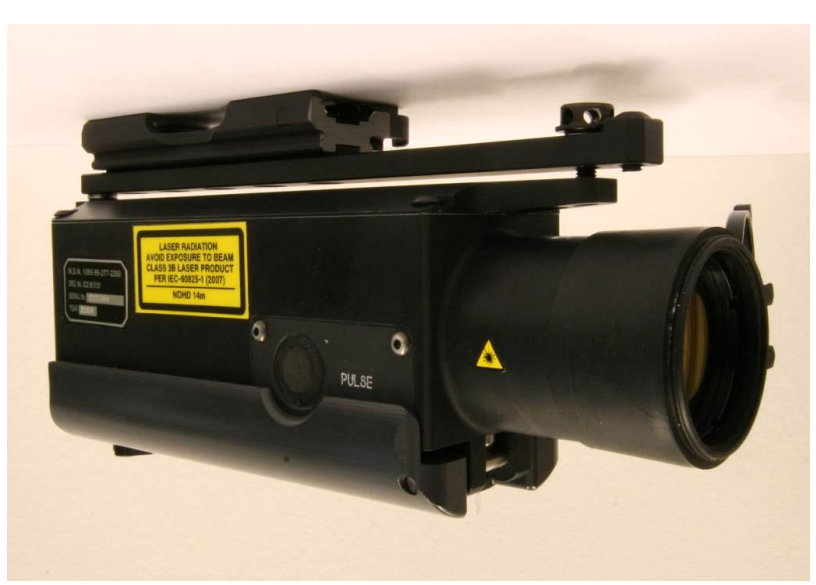

(a)

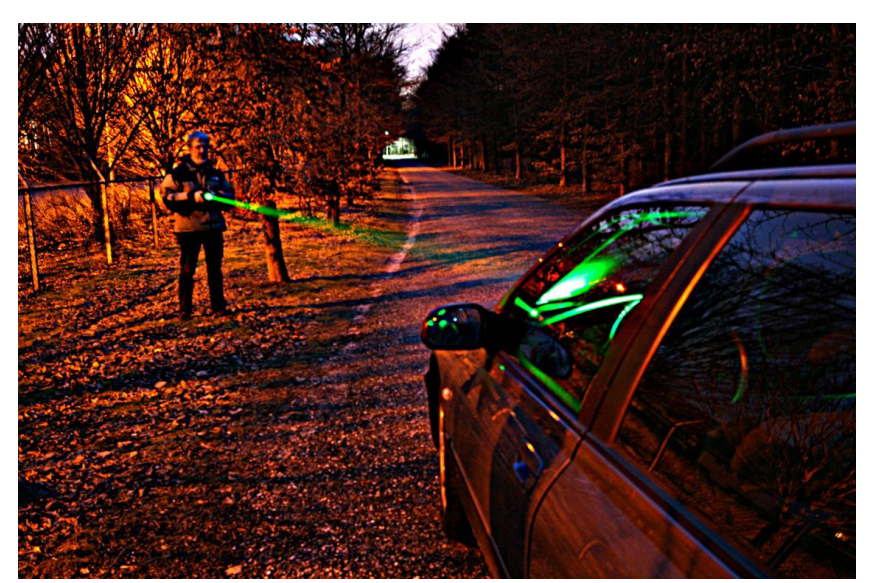

(b)

Figure 3. (a) The Green Light Optical Warner MK3 (GLOW). (b) Operator aiming the beam of a GLOW on the windscreen of an approaching vehicle.

From the results we derived a method to assess the possible impact of windscreen illumination by a high intensity light source on driving behavior. This assessment can be directly related to operational requirements and can therefore be used to assess the effectiveness of high intensity light sources. In addition, we also developed an associated test protocol to assess the effectiveness of high intensity light sources in denying car drivers their view on the outside world through windscreens (details reported elsewhere ${ }^{16}$ ).

\subsection{The GLOW light source}

The high intensity light source used in this study was a GLOW Green Light Optical Warner MK3 or GLOW ${ }^{17}$. The GLOW is a gun-mounted battery operated non-lethal (Class 3B) laser warning light (Figure 3a). It is designed to enhance the safety and capabilities of military and security forces, especially in areas where civilians and insurgents are difficult to differentiate. The GLOW can be used to provide protection against potential aggressors at vital points such as civil or military installations, vehicle checkpoints and convoys. The intense green light beam of the GLOW can be used to warn approaching persons that they are under suspicion and should not approach any further. It may further be used to degrade the ability of aggressors to continue with their undesired (offensive) actions (Figure $3 b$; for impressions of the visua effects see also Figs. 4 and 5).

The GLOW can be gun mounted (underslung position) using a Picatinny Rail, operated remotely or used hand-held with a pistol grip or stock. The GLOW features two beam modes: a wide beam mode for use in urban scenarios, or a narrow beam mode for deployment at longer ranges. In both modes the beam can be used in a continuous mode, or in a pulsed mode to elicit a higher level of attention. Note that selecting 'narrow' requires an automated mechanical adjustment of the beam width each time the GLOW is operated.

\subsection{Illuminance measurements}

We measured the illuminance as a function of the distance from the GLOW, operating respectively in its wide and narrow beam mode, using a calibrated illuminance meter (LMT, Berlin, Germany). The sensor of the illuminance meter was located in the center of the beam and its surface was oriented perpendicular to the beam, while facing the light source. The illuminance produced by the GLOW was measured at 11 different distances ranging from 0 to 56 meters. Illuminances at larger distances from the light source can be extrapolated using the following inverse square law:

$$
E=\frac{I}{d^{2}}
$$

with:

$$
\begin{aligned}
& E=\text { illuminance }(\mathrm{lx}) . \\
& I=\text { luminous intensity }(\mathrm{cd}) . \\
& d=\text { distance from light source }(\mathrm{m}) .
\end{aligned}
$$

The luminous intensity of the laser was derived from the measured illuminances using equation (4). 

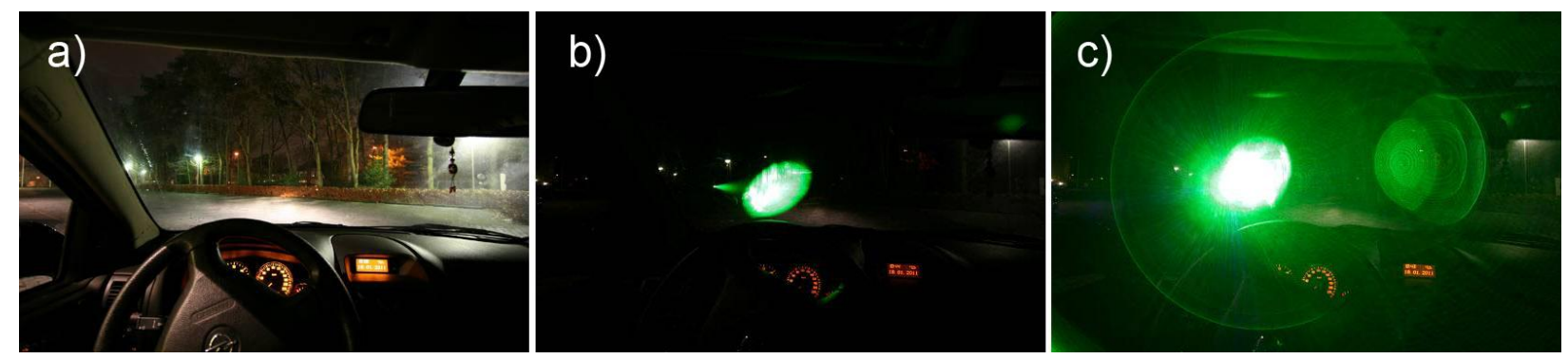

Figure 4. Nighttime scene with artificial illumination, seen from the position of the driver, (a) with no visual interference and with the GLOW in respectively (b) the narrow and (c) the wide beam mode, aimed at the windshield from a distance of about $15 \mathrm{~m}$ and an angle of about 40 degrees (the GLOW was directed at the driver from the left side of the car).
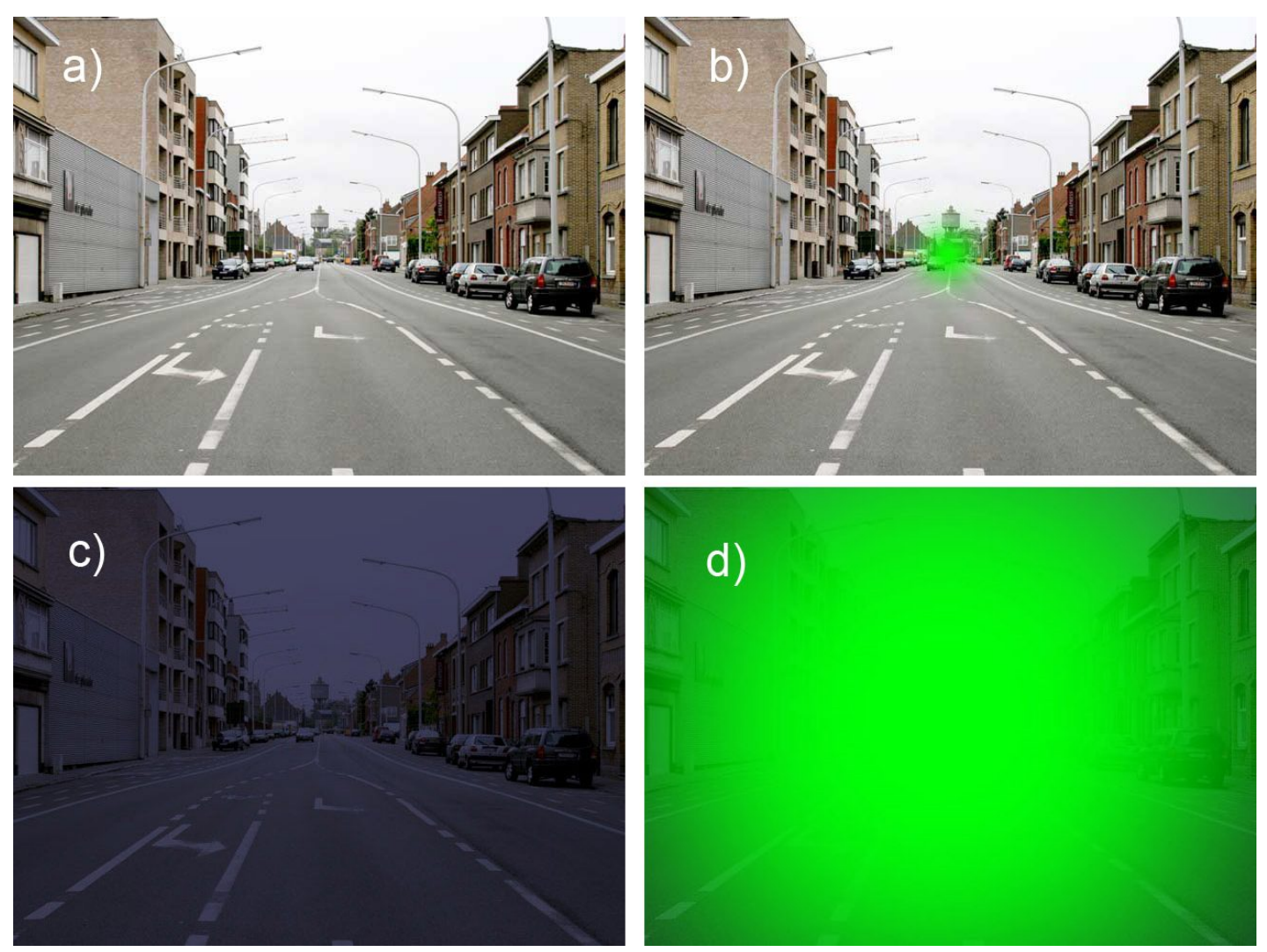

Figure 5. Road view, seen from the position of the driver. Left column (a,c): undisturbed daytime (a) and nighttime (c) view. Right column (b,d): daytime (b) and nighttime (d) view with the GLOW aimed at the windshield from straight ahead and in the narrow beam mode. 


\subsection{Beam width measurements}

The width of the beam produced by the GLOW was determined as follows.

- The beam was projected orthogonally at a diffuse reflecting white surface.

- The resulting luminance distribution on this surface was registered with a calibrated luminance camera

(TechnoTeam, LMK mobile Rollei d30flex).

- The maximal luminous intensity at the center of the beam was determined.

- The beam width was computed, defined as the diameter of a circular area that contains $63 \%$ of the total laser power (1/e points).

We determined the beam width at distances of 5, 20 and $50 \mathrm{~m}$ from the GLOW.

\subsection{Windscreens}

We used seven different types of windscreens of current passenger car models in this study (for details see ${ }^{16}$ ). For five types we had both new and used windscreens. The test set was selected such that it included windscreens of different colors (blue, green, white and bronze), shapes, conditions and sizes (for details see ${ }^{16}$ ).

\subsection{Scratches and dirt}

We assessed the effects of scratches and dirt on the veiling luminance $\left(\mathrm{L}_{\mathrm{v}}\right)$ that appears when a light source is directed to a windscreen. The effect of scratches was taken into account by measuring glare effects for both new and used windscreens. The effect of dirt was introduced by coating some of the windscreens with a salt film, to simulate road salt spray that dries in place on a windscreen during winter driving conditions. The salt film was applied to the windscreens by spraying a saline solution across the entire viewing area in three even coats and then allowing it to dry. The solution was prepared and applied according to a standardized procedure ${ }^{16,18}$.

\subsection{Scatter measurements}

The light scatter measurements were performed by WTD-91 (Wehrtechnische Dienststelle für Waffen und Munition, Meppen, Germany), in a long lightproof corridor with black walls.

A stand was built to hold each windshield at a mounting angle between 5 and 10 degrees from the vertical. The actual mounting angle is not critical for the present experiments, since previous studies by $\mathrm{TNO}^{19}$ found that the glare resulting from (clean or dirty) windows only depends on the angle between the viewing direction and the light source, and is therefore independent of the orientation of the windshield.

A calibrated luminance meter (LMT-L1009, Lichtmesstechnik GmbH, Berlin, Germany) was placed behind the windshield (i.e., at the side of the driver), looking through the windshield in the direction of a black hole that was placed in front of the windshield.

The black hole consists of an elongated wooden box $\left(\mathrm{W} \times \mathrm{H} \times \mathrm{L}=50 \times 50 \times 100 \mathrm{~cm}^{3}\right)$ with non-reflecting black walls and a shiny black plate mounted deep inside at an angle of 45 degrees relative to the main (length) axis of the box. This box has a luminance factor of about 0.0003 . As a result, in the configuration used in this experiment the luminance meter only measures light reflected (scattered) by the windscreen.

The GLOW was placed in front of the windshield, and oriented such that the center of its beam coincided with the center of the windshield. The luminance meter was focused at the center the windscreen, using an aperture size of 1 degree. A round aperture in a wooden panel covered with non-reflecting black paint prevented light from the GLOW to directly enter the aperture of the luminance meter. As a result the luminance meter only measured light that was dispersed by the windshield. Measurements performed with the GLOW turned off provided estimates of the straylight coming from the ambient lighting in the room. This background straylight level was subtracted from the veiling luminance that was measured when the GLOW illuminated the windshield, to obtain the veiling luminance that resulted only from the beam 
of the GLOW itself. Measurements were performed for several angles $\alpha(\alpha=0,7,13.4,19.9,40.6$, and 59.7 degrees) between the beam of the GLOW and the horizontal component of the normal on the windshield. As a result the glare angle $\theta$ between the viewing direction and the incoming beam of the GLOW varied between approximately 10 and 45 degrees. Note that the range of measurements was limited by the dimensions of the corridor and that two test arrangements made use of a mirror. We observed no significant reduction of the luminance distribution over the scene due to the presence of the mirror.

A calibrated LMK-98-4 video photometer (TechnoTeam Bildverarbeitung GmbH, Ilmenau, Germany) was placed at the approximate eye position of the hypothetical driver, looking sideways through the windshield towards a contrast test chart placed in front of the windshield. The camera photometer was interfaced with a Dell Latitude E6500 laptop computer. LMK LabSoft software (TechnoTeam Bildverarbeitung GmbH, Ilmenau, Germany) was used to register, analyze and visualize the luminance images of the contrast chart. LMK LabSoft's HighDyn-algorithm was used to capture luminance images composed of a collection of multiple single images registered at various integration times so as to realize a higher dynamic range.

Room illuminance (resulting from the fluorescent lamps mounted on the ceiling and some additional beamers) was respectively $10^{-4}, 10^{3}$ or $10^{4} \mathrm{~lx}$, and was measured at, and orthogonal to, the surface of the contrast chart, using a calibrated illuminance meter (Lichtmesstechnik GmbH, Berlin, Germany).

\subsection{Scatter functions}

Dirt and scratches cause an additional veiling luminance $\left(\mathrm{L}_{\mathrm{v}}\right)$ when a high intensity light source is directed at a windscreen. This veiling luminance reduces the contrast of objects in the scene and reduces the distance at which objects are visible for the driver of the car. The veiling luminance is described by

$$
L_{v}=f(\theta) \cdot E=a \theta^{b} . E
$$

where $\theta$ is the angle between the driver's viewing direction and the radiation direction, and $\mathrm{E}$ represents the illuminance $\mathrm{E}$ (measured perpendicular to the radiation direction) on the windscreen.

The function $f(\theta)$ is called the scatter function. The scatter function can be described by a power function with a constant factor a and an exponent b. Padmos \& Alferdinck ${ }^{19,20}$ measured the scatter function of 25 used dirty and clean windscreens. It appears that the scatter function for an average (dirty) windscreen on the road can be modeled by the following function:

$$
\begin{aligned}
& f(\theta)=44 \theta^{-2.6}, 9^{\circ}<\theta<110^{\circ} \\
& f(\theta)=6.6 \theta^{-1.73}, 1^{\circ}<\theta<9^{\circ}
\end{aligned}
$$

The scatter function for clean windscreens is one fifth of the scatter function for average dirty windscreens. In that case the equations (6) must be multiplied by 0.2 .

In the current study the scatter function was measured for 12 different new (5) and used (7) windscreens. Most of these windscreens were also measured both in a dirty and clean condition.

\subsection{Assessment of impact on driving behavior}

We derived a method to assess the possible impact of the illumination of a windscreen by a high intensity light on driving behavior. We hypothesize that driving behavior is affected by the capability to detect distant objects on the road. The veiling luminance that occurs when incoming light is scattered by the windscreen and the driver's eyes compromises this capability. As a result, the detection distance of objects on the road will decrease and drivers will be inclined to reduce their speed, because they become less secure and feel the need to adjust their stopping distance to the maximum viewing distance. As an example we calculated the detection distance of an object (stone) on the road at night-time. The detection distance depends on the properties of the observer (age, eyes), car (size, headlamps), light source (luminous intensity, distance), and road surface (reflection) and object (size, reflection). The geometry of the calculation of the detection distance is shown in Figure 6. 


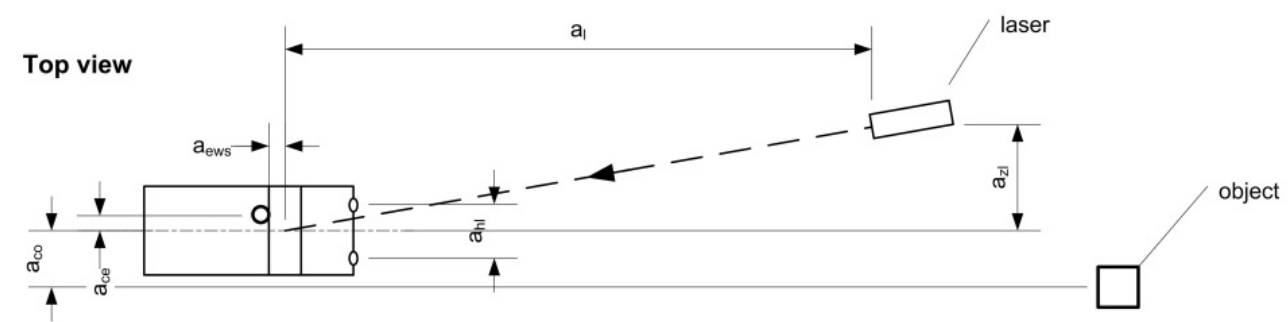

Side view

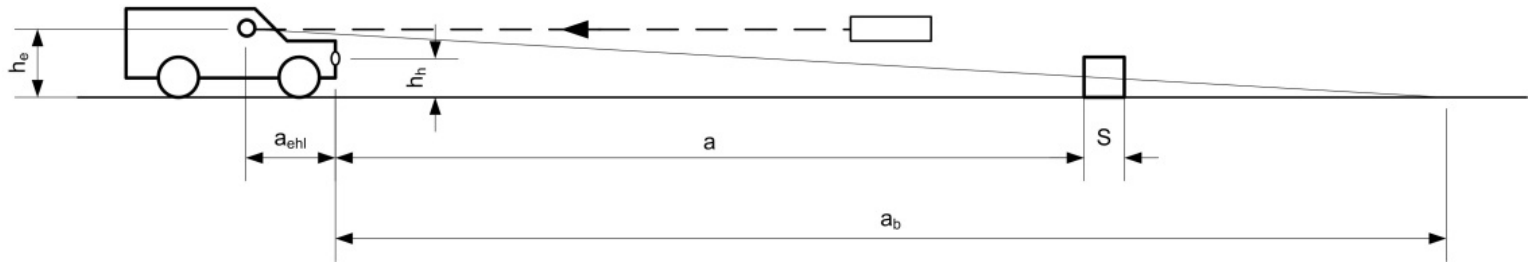

Figure 6. Geometry of the calculation of the detection distance of an object on the road in front of the car. The small circle represents the observer.

The calculation procedure was as follows. As a characteristic obstacle we adopted a cube $(20 \mathrm{~cm} \times 20 \mathrm{~cm} \times 20 \mathrm{~cm})$ with same diffuse reflection coefficient as the road (0.2). This simulates a rock of the same color as the road, that the driver needs to see in time in order to avoid car damage. Other parameters used in this example are listed in Table 2. The car headlamps illuminate both the object and its background. For the luminous intensity of the dipped- (or passing-) beam headlamp we used the 50-percentile data of a European headlamp ${ }^{21}$. For the driving beam we added an extra beam to the passing beam with a luminous intensity of $30,000 \mathrm{~cd}$ in the center and a beam width of about 5 degrees (at $50 \%$ of the maximum intensity ${ }^{22}$ ). The illuminance of the object was calculated by dividing the luminous intensity of both headlamps in the direction of the object by the square of the distance. The luminance of the object $L_{o}$ is the object illuminance times the refection coefficient divided by $\pi$. The background luminance $L_{b}$ is the luminance next to the center of the object at a distance $a_{b}$ in front of the car, calculated in a similar way.

The effect of the veiling luminance of eye and windscreen is introduced by adding the veiling luminance to both the object and background luminance. Note that the veiling luminance decreases the contrast of the object (see equation (2)). The contrast of the object and the visual angle of the object were calculated for distances between 10 and $1000 \mathrm{~m}$. Both contrast and visual angle decrease with increasing distance. The human eye can perceive an object when its size (in visual angle) and its contrast with the background is sufficiently large, or above contrast threshold. We used the model of Adrian ${ }^{13}$ for the calculation of the contrast threshold for the size of the object at the various distances. At large distances the illumination of the object is poor and its size is small, the object contrast will be below threshold. At short distances, when the car approaches the object, the threshold will be exceeded and the object becomes visible. The object is just detectable at the distance at which the contrast is equal to the contrast threshold. This is called the detection distance.

The detection distance was calculated for different windscreen conditions (no windscreen, clean and dirty windscreen), and with or without stray light in the eye (disability glare). The luminous intensity varied from zero to 1 Mcd. The results of the calculations are presented in the next section of this report. 
Table 2. Parameters used in the example calculation of the distance at which a car driver can detect an object on the road in darkness, when the windscreen is hit by the beam of a GLOW MK3.

\begin{tabular}{|c|c|c|}
\hline Parameter & Value & Remarks \\
\hline \multicolumn{3}{|l|}{ Object } \\
\hline Object size (cube) S (m) & 0.2 & \\
\hline Lateral distance object to centre of car $\mathrm{a}_{\mathrm{co}}(\mathrm{m})$ & 2 & Right side from observer \\
\hline Luminance factor object $\beta_{\mathrm{o}}$ & 0.2 & \\
\hline Luminance factor road $\beta_{\mathrm{r}}$ & 0.2 & \\
\hline \multicolumn{3}{|l|}{ Car } \\
\hline Height headlamp $\mathrm{h}_{\mathrm{h}}(\mathrm{m})$ & 0.64 & Car dimensions based on Opel Astra station wagon \\
\hline Distance eye to windscreen $\mathrm{a}_{\mathrm{ew}}(\mathrm{m})$ & 0.68 & \\
\hline Lateral distance eyes to centre of car $\mathrm{a}_{\mathrm{ce}}(\mathrm{m})$ & 0.32 & \\
\hline Distance between headlamps $\mathrm{a}_{\mathrm{hl}}(\mathrm{m})$ & 1.24 & \\
\hline Distance eyes to headlamps $\mathrm{a}_{\mathrm{ehl}}(\mathrm{m})$ & 1.9 & \\
\hline Transmission factor windscreen & 0.82 & (average measurement WTD-91) \\
\hline Deceleration $\left(\mathrm{m} / \mathrm{s}^{2}\right)$ & 2.5 & Comfortable stopping \\
\hline \multicolumn{3}{|l|}{ Laser } \\
\hline Distance laser to windscreen $\mathrm{a}_{1}(\mathrm{~m})$ & 100 & \\
\hline Lateral distance laser to windscreen $\mathrm{a}_{\mathrm{zl}}(\mathrm{m})$ & 3 & Right from observer, at eye height \\
\hline Luminous intensity laser in the centre of the beam (cd) & 62,000 & (GLOW in wide beam mode, measured by TNO) \\
\hline Laser divergence $\mathrm{D} 63 \%$ (mrad) & 21 & (GLOW in wide beam mode, measured by TNO) \\
\hline \multicolumn{3}{|l|}{ Observer } \\
\hline Height eye $h_{e}(m)$ & 1.2 & \\
\hline Age observer (years) & 30 & \\
\hline Pigmentation factor eyes & 1 & $\mathrm{CIE}^{15}$ \\
\hline Reaction time (s) & 1.5 & \\
\hline Field factor & 10 & Adrian (1989) \\
\hline
\end{tabular}

\section{RESULTS}

\subsection{Luminous intensity and beam width}

Figure 7 shows the illuminance (lx) produced by the GLOW as a function of distance (m), for respectively the narrow and wide beam modes. Also indicated in this figure are the (critical) distances below which the threshold (critical) levels for certain visual effects (startle, distraction; glare, afterimages, flash blindness; damage) are exceeded. The distance below which the Maximum Permissible Exposure (MPE) level is exceeded and lasting eye damage may occur. The Nominal Ocular Hazard Distance or $\mathrm{NOHD}^{23}$ is $6 \mathrm{~m}$ in the narrow beam mode and $2 \mathrm{~m}$ in the wide beam mode. Afterimages and flash blindness may occur at distances below $30 \mathrm{~m}$ in the narrow beam mode and $10 \mathrm{~m}$ in the wide beam mode. Glare may be experienced at distances below $130 \mathrm{~m}$ in the narrow beam mode and $45 \mathrm{~m}$ in the wide beam mode. Finally, the GLOW may cause distraction at distances below $1300 \mathrm{~m}$ in the narrow beam mode and $425 \mathrm{~m}$ in the wide beam mode. These results hold for the observation with the naked eye. For viewing through a windscreen the critical distances should be multiplied by the transmission factor of the windscreen (typically about 0.82 - thus, the critical distances will be about 0.82 smaller due to the attenuation of the beam by the windscreen). 

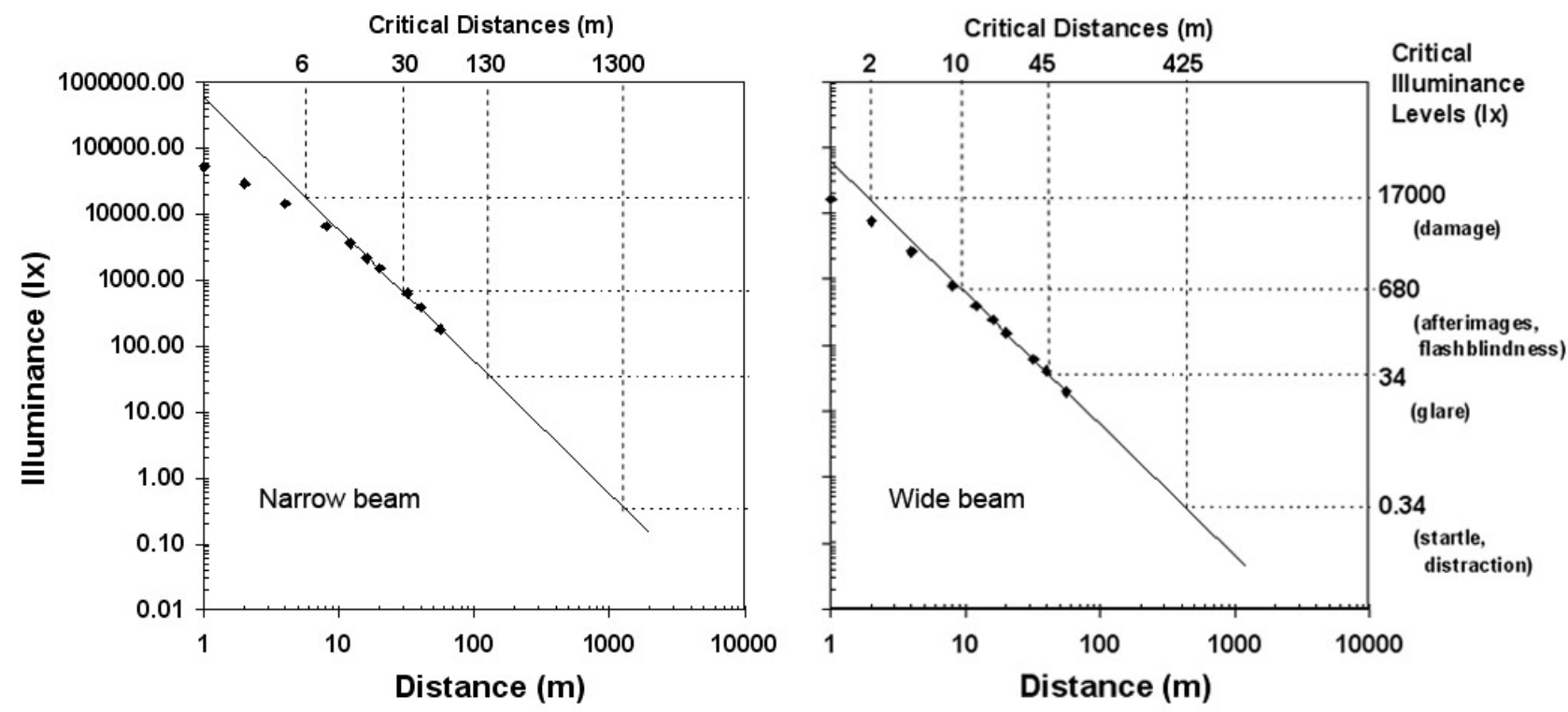

Figure 7. The illuminance (lx) produced by the GLOW operating in the narrow (left) and wide (right) beam mode, as a function of distance (m). Also indicated are the (critical) distances below which the threshold (critical) levels for different visual effects (startle, distraction; glare, afterimages, flash blindness; damage) are exceeded.

The luminous intensities at the center of the beam and the average beam width are listed in Table 3 . Note that the beam width is defined as the diameter of a circular area that contains $63 \%$ of the total laser power (1/e points). The last column shows the diameter of the light spot at a distance of $100 \mathrm{~m}$.

Table 3. Measured luminous intensities and width of the beam of the GLOW in respectively the narrow and wide angle mode.

\begin{tabular}{|llll|}
\hline Mode & $\begin{array}{l}\text { Luminous intensity in the centre of the } \\
\text { beam }(\mathrm{cd})\end{array}$ & $\begin{array}{l}\text { Beam width (D63\%) } \\
(\mathrm{mrad})\end{array}$ & $\begin{array}{l}\text { Diameter at } 100 \mathrm{~m} \\
\text { distance }(\mathrm{m})\end{array}$ \\
\hline Narrow & 590,000 & 7.2 & 0.72 \\
Wide & 62,000 & 21 & 2.1 \\
\hline
\end{tabular}




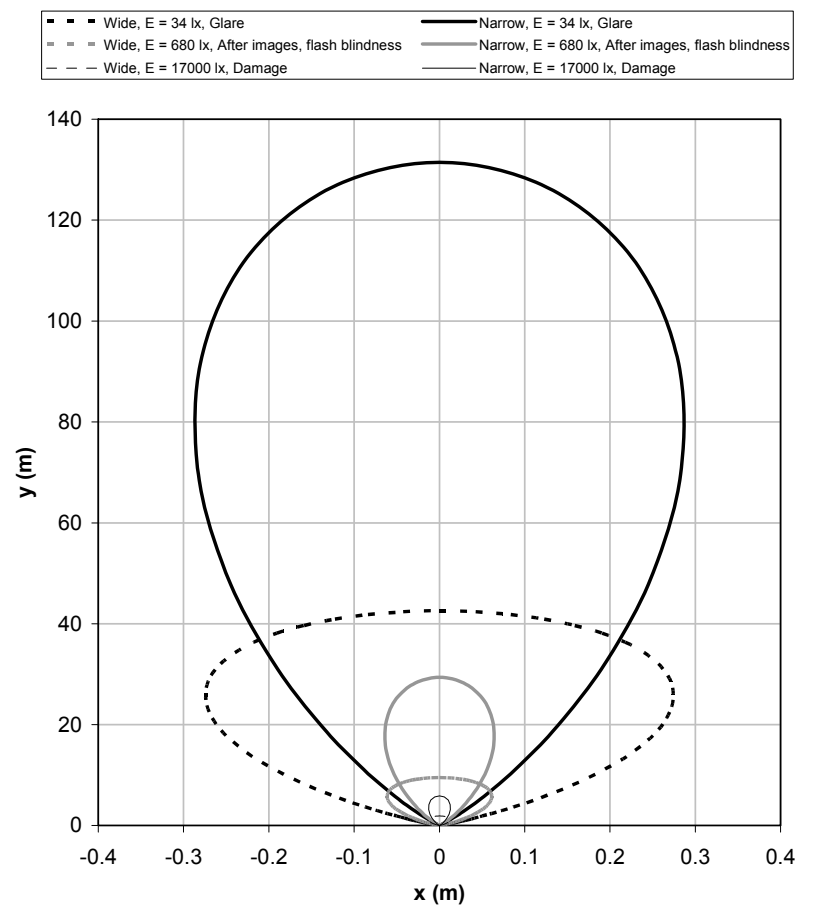

Figure 8. Range of the GLOW beam in its narrow and wide mode as a function of the forward (y) and sideward (x) positions relative to the laser. Indicated are lines of constant illuminance (E) that indicate the critical distances below which various critical visual effects can occur.

\subsection{Windscreen scatter function}

The windscreen scatter functions measured by WTD-91 are plotted in Figure 9. Data points measured for values of the glare angle $\theta$ (the angle between the driver's viewing direction and the radiation direction) between 8 and 50 degrees were fitted with a scatter function of the form $f(\theta)=a \cdot \theta^{b}$. (see equation (5). Note that this function is represented by a straight line on the log-log graph in Figure 9. As expected the scatter is largest for the smallest glare angles in all conditions. This is also reflected by the negative values of the exponent $b$, which varies between -1.50 and -2.29 . Dirt also has a significant effect on scatter by the windscreen.

The measured scatter values for dirty windscreens are consistently larger than those measured for clean windscreens. There is no statistical significant difference between dirty, new and dirty, used windscreens $(p=0.83)$. Also the difference between clean, new and clean, used windscreens is not significant, although there is a trend that used windscreens scatter more than new windscreens $(\mathrm{p}=0.096)$. This is probably due to the extra amount of surface scratches on used windows. The scatter function of the dirty windscreens (both used and new) does not differ significantly from the model of Padmos $\&$ Alferdinck $^{19,20}$ and is described by this model for glare angles between of 9 and 110 degrees: $f(\theta)=44 \theta^{-2.6}$ (see equation (6)). Since there is no statistical significant difference between the scatter functions for used and new windscreens, we combined the data for new and used windscreens in the calculation of the effect of dirt. On average the scatter function for dirty windscreens is a factor 14 larger than for clean windscreens. Since the models with the four exponents $b$ between -1.50 and -2.29 describe the data not statistically significant better than the model of Padmos \& Alferdinck $^{19,20}$ with an exponent of -2.6 , we decided to use the model of Padmos \& Alferdinck ${ }^{19,20}$ for further calculations. The effect of cleaning can be accounted for by dividing the scatter function for dirty windscreens by a factor 14. Figure 9 shows the model fits for respectively clean and dirty windscreens according to Equation (6). Note that for glare angles below 9 degrees the model of Padmos \& Alferdinck ${ }^{19,20}$ has an exponent of -1.73 , which results in a less steep function. Finally, there appears to be no significant effect of windscreen color on the measured scatter values. 


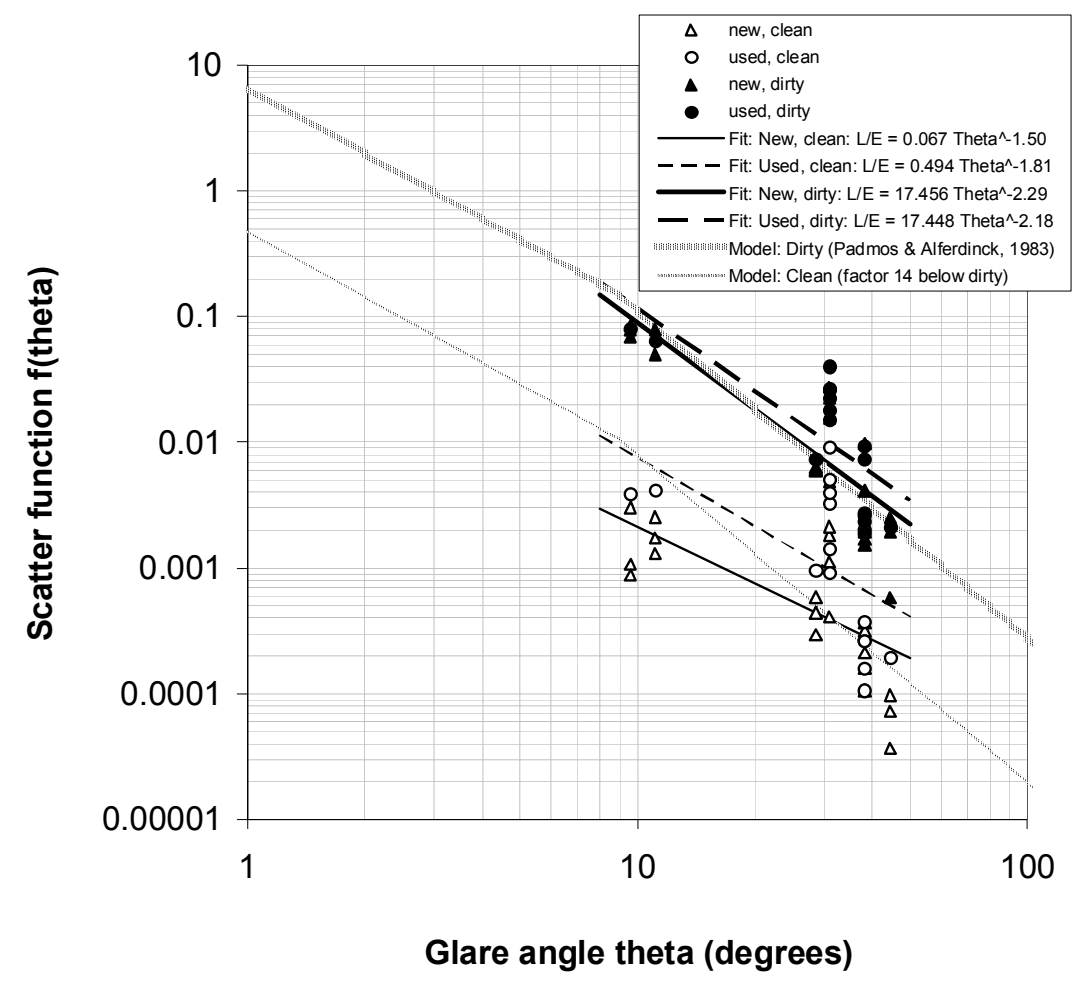

Figure 9. Measured scatter functions of new and used windscreens in dirty and clean states, compared with the scatter model for dirty windscreens from Padmos \& Alferdinck ${ }^{19,20}$. Also shown is a scatter model for clean windscreens derived by dividing this model by a factor 14 . The measured scatter data are fitted with a function of the form $f(\theta)=a \cdot \theta^{b}$.

\subsection{Detection distance}

Figure 10 shows the detection distances of the object for the conditions headlamp type (passing beam, driving beam), disability glare (no disability glare / disability glare), windscreen condition (no windscreen, clean, dirty), and presence of the GLOW laser with a wide (left) or narrow (right) beam.
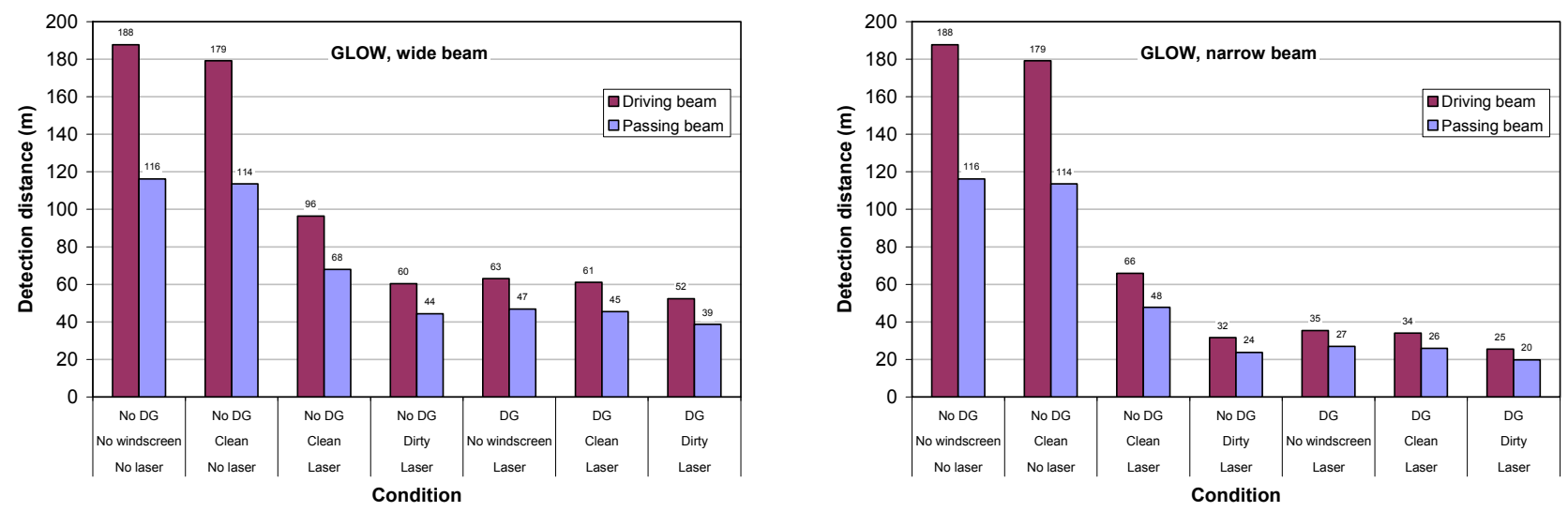

Figure 10. Detection distances for the different disability glare conditions (no Disability Glare / Disability Glare), the windscreen conditions (Clean, Dirty), and the presence of the light source (no lase/laser), with the GLOW operating in respectively its wide (left) and narrow (right) beam mode. 
The largest detection distances are obtained in the conditions without a windscreen and without a light source. In that case the veiling luminance due to both the light source and the eye (disability glare) is zero and the object can be detected at $188 \mathrm{~m}$ or $116 \mathrm{~m}$ when using respectively the driving and passing beam. When the observer looks through a clean windscreen the detection distance drops somewhat due to the absorption of the windscreen.

When the driver looks through a clean windscreen and the GLOW is switched on, the detection distances in the wide beam mode and in the narrow beam mode are reduced to respectively $60 \%$ and $40 \%$ of their original values, due to straylight in the eye (disability glare). With a dirty windscreen the detection distances decrease to about one third in the wide beam mode and one fifth in the narrow mode when the GLOW is turned on.

Disability glare occurs when the GLOW is in the visual field of the driver (when the light source is not obstructed). With disability glare the detection distances decrease significantly. The detection distances with disability glare are similar to those obtained with a dirty windscreen and no disability glare. The shortest detection distances are achieved when the laser is in operation and visible for the driver (disability glare) and the windscreen is dirty. The detection distances are reduced by a factor of about 0.3 in the wide beam mode and 0.15 in the narrow beam mode when the GLOW is turned on.

To estimate the effect of the GLOW on the detection distance we varied the luminous intensity of the laser beam in our calculations from $10 \mathrm{~cd}$ to $1,000,000 \mathrm{~cd}$. The results are plotted in Figure 11 for a situation in which the GLOW causes no disability glare (left) and for a situation in which the GLOW does cause disability glare (right). The vertical dotted line segments indicate the luminous intensities of the GLOW laser in the narrow (right line segment) and wide (left line segment) beam modes respectively. When the luminous intensity of the GLOW increases the detection distance decreases. As expected, the largest detection distances are obtained for the driving beam in combination with a clean windscreen and the lowest are achieved for the passing beam in combination with a dirty windscreen.

Note that all curves show a discontinuity at $500 \mathrm{~cd}$ for the condition without disability glare and at $50 \mathrm{~cd}$ for the condition with disability glare. These discontinuities are caused by the transition between scotopic and photopic vision by the retinal rods and the cones, respectively. This effect is also illustrated in Figure 1 which shows that the contrast threshold as a function of the background luminance has discontinuities according the model of Adrian ${ }^{13}$, which we used for these calculations.

The luminous intensity and the distance between the laser and the windscreen are interchangeable to a certain extent. In the current calculations we assumed that the GLOW was positioned at $100 \mathrm{~m}$ in front of the windscreen. According to equation (4) the irradiance at the windscreen is then $1 / 10,000$ times the luminous intensity. A GLOW with a luminous intensity of $62,000 \mathrm{~cd}$ therefore causes an irradiance of $6.2 \mathrm{~lx}$ at $100 \mathrm{~m}$. distance. The same irradiance can be obtained with a light source of $62,000 / 4=15,000 \mathrm{~cd}$ at $50 \mathrm{~m}$ distance. This will cause the same veiling luminance, when the glare angle is about the same.
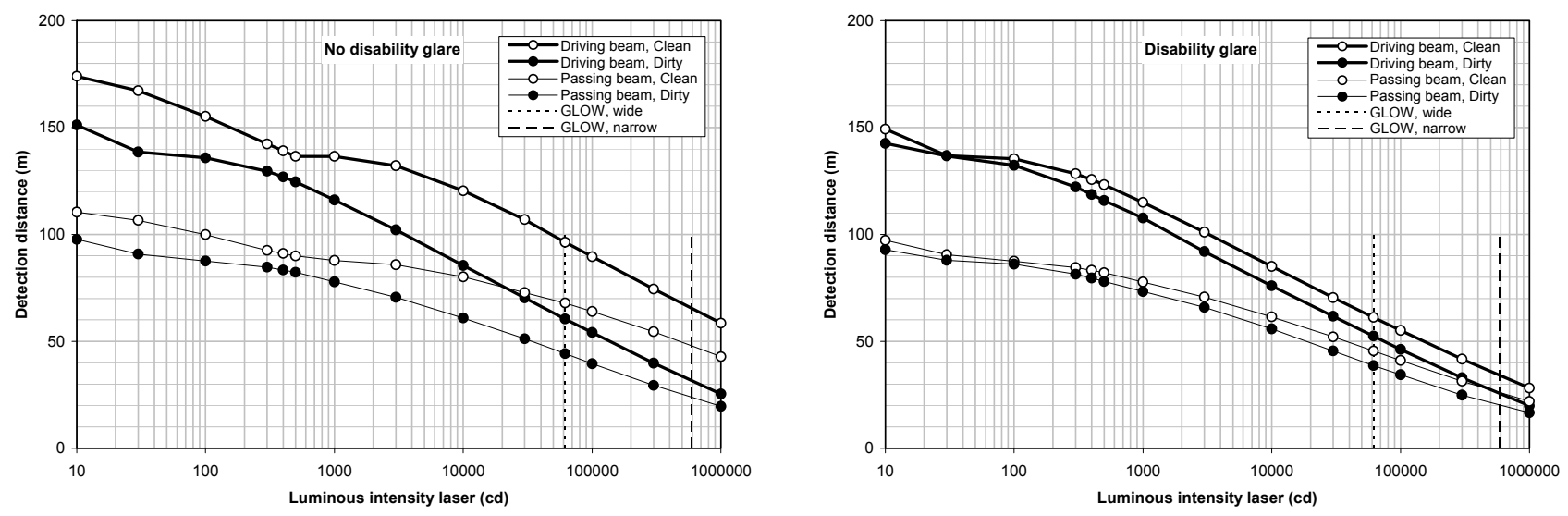

Figure 11. Detection distance as a function of the luminous intensity of the laser (measured in the center of the beam) for driving and passing beam of the headlamp and with a clean or dirty windshield, when the GLOW causes no disability glare (left), or when it does cause disability glare (right). 


\section{POSSIBLE EFFECTS ON DRIVING BEHAVIOR}

We found that a light source with sufficient luminous intensity shining on a windscreen of a car can reduce the detection distance of an object (e.g. rock) by a factor larger than 3. The question now is: What is the minimum luminous intensity required to stop or significantly reduce the speed of an approaching car? This will of course depend on the driver's intent and behavior, but we can assume that a benign driver will reduce his speed or even stop the car when he is no longer able to see objects at a distance comparable to or smaller than the stopping distance. The stopping distance is given by:

$$
d=t_{r} \cdot v+\frac{v^{2}}{2 a}
$$

where $t_{\mathrm{r}}$ represents the reaction time in $\mathrm{s}, v$ the driving speed in $\mathrm{m} / \mathrm{s}$, and $a$ the deceleration in $\mathrm{m} / \mathrm{s}^{2}$. The reaction time is usually about $1.5 \mathrm{~s}$. A deceleration of $2.5 \mathrm{~m} / \mathrm{s}^{2}$ is considered comfortable, whereas a deceleration of $5 \mathrm{~m} / \mathrm{s}^{2}$ occurs in case of an emergency stop ${ }^{24}$. Figure 12 shows the stopping distance as function of the driving speed for both comfortable stopping and emergency stop conditions.

The stopping distance from Figure 12 can be used to calculate the maximum save driving speed that drivers will adopt on basis of the visibility of potential objects on the road. We calculated this driving speed by transforming equation (7) in:

$$
v_{\max }=3.6 a\left(\sqrt{t_{r}^{2}+\frac{2 d}{a}}+t_{r}\right)
$$

where $v_{\max }$ represents the maximum save driving speed in $\mathrm{km} / \mathrm{h}$, a the deceleration in $\mathrm{m} / \mathrm{s}^{2}, t_{r}$ the reaction time in $\mathrm{s}$ and $d$ the detection distance in $\mathrm{m}$. With this equation the detection distances of Figure 11 are converted into maximum save driving speeds. The results are plotted in Figure 13.

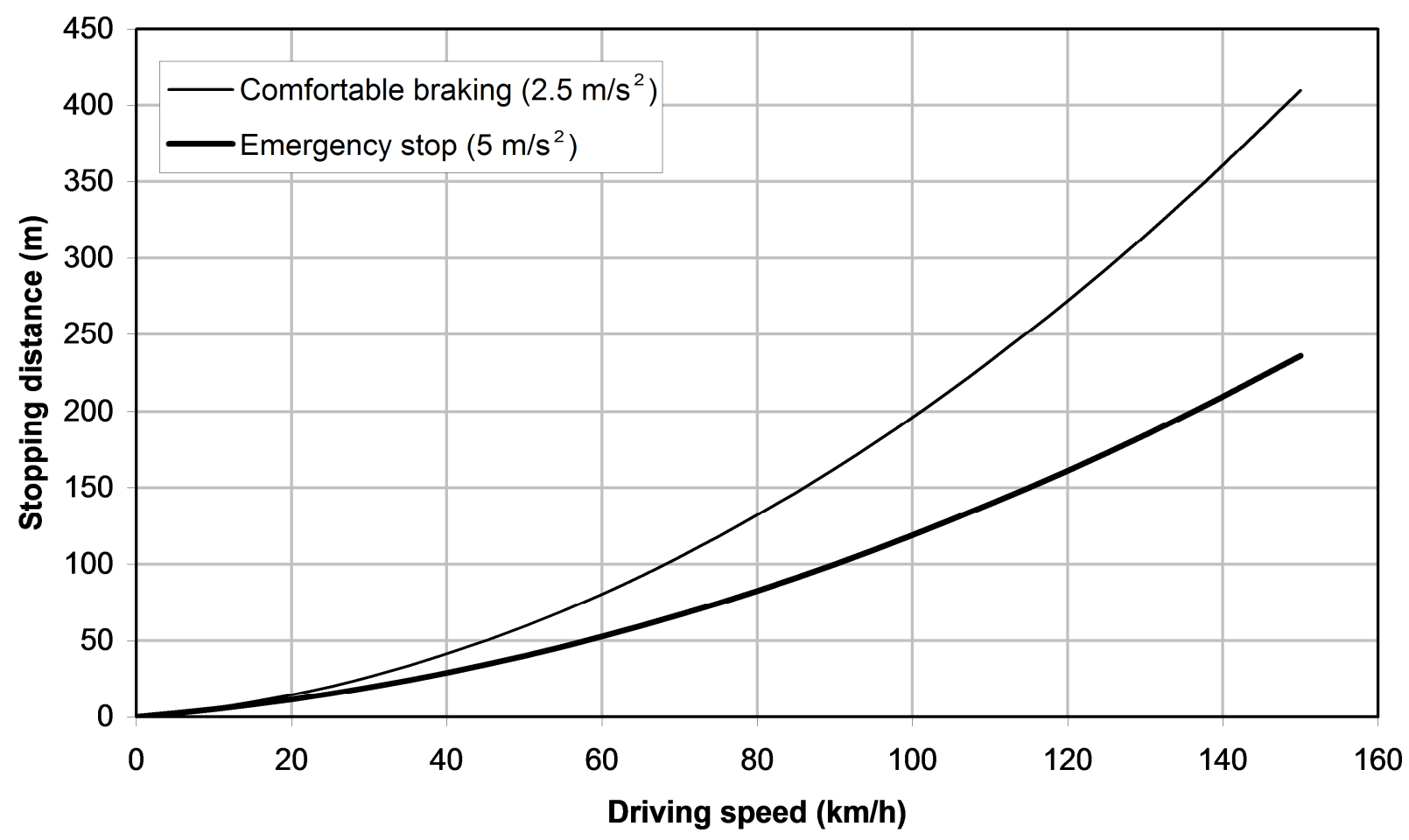

Figure 12. Stopping distance as a function of driving speed. The reaction time is $1.5 \mathrm{~s}$. 

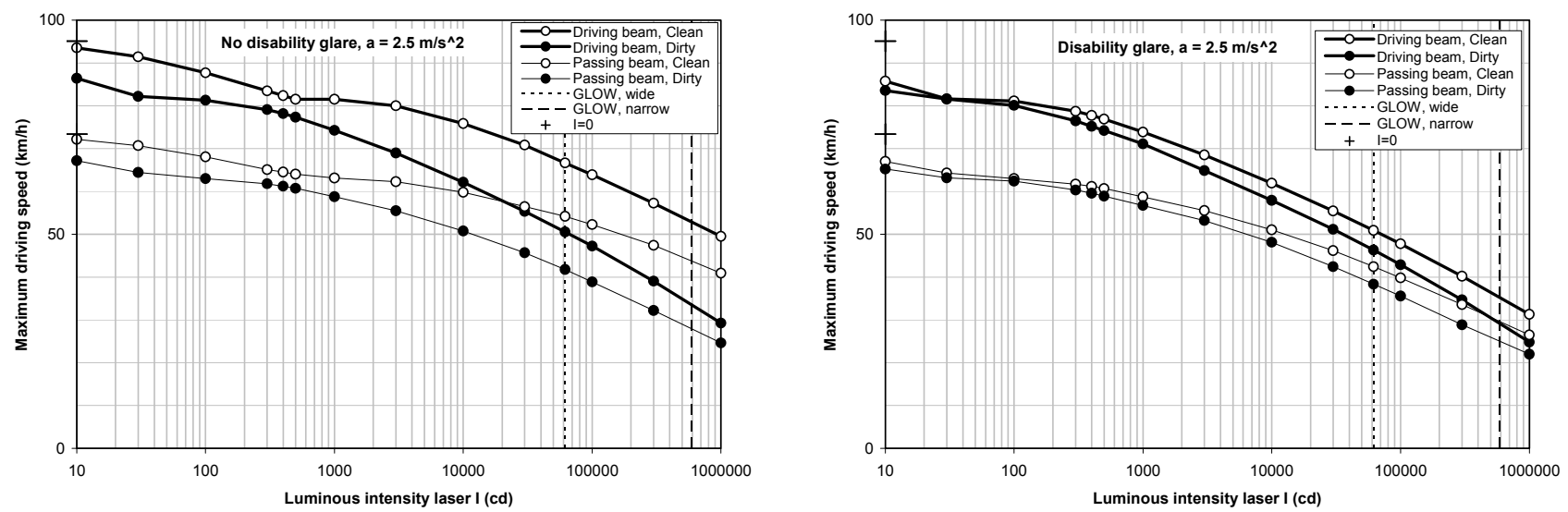

Figure 13. Maximum save driving speed as a function of the luminous intensity of the laser (measured in the centre of the beam), for the driving and passing beam of the headlamp and with a clean and dirty windshield. The deceleration is $2.5 \mathrm{~m} / \mathrm{s}^{2}$. The horizontal markings at the left vertical axis indicate the maximum save driving speed when the GLOW is switched off $(\mathrm{I}=0)$. The left and right figures respectively show the result without and with disability glare due to the GLOW.

Figure 13 shows that maximum save driving speed consistently decreases with increasing luminous intensity of the laser. For the GLOW laser in the wide mode, with a luminous intensity of more than $60,000 \mathrm{~cd}$, the maximum save driving speed is below $50 \mathrm{~km} / \mathrm{h}$ with a typical dirty windscreen and driving beams. For passing beams the maximum save driving speed is about $40 \mathrm{~km} / \mathrm{h}$ in this condition. For the GLOW laser in the narrow mode, when its luminous intensity is almost a factor 10 more than in the wide mode, the maximum save driving speed is approximately $30 \mathrm{~km} / \mathrm{h}$. With a clean windscreen and driving beams the maximum save driving speed is between 50 and $70 \mathrm{~km} / \mathrm{h}$ for the wide beam, and between 45 to $52 \mathrm{~km} / \mathrm{h}$ for the narrow beam. Since the average windscreen is not clean (both the inside and outside are typically dirty and in practice drivers typically start to clean their windows when the amount of dirt becomes cleanly noticeable; see ${ }^{20}$ ) only the dirty windscreen condition should be considered in practice.

The luminous intensity of the GLOW laser in wide mode is $62,000 \mathrm{~cd}$ in the center of the beam. This luminous intensity is about the same as the sum of the intensities of the two driving beams of an oncoming car, which are at least 30,000 cd each. In practice most drivers don't stop when confronted with the glare due to the driving beams of an oncoming car, but they may reduce their driving speed. Moreover, it has been observed that most drivers choose a speed which is too high to stop for an obstacle ${ }^{25}$.

The stopping power of the laser probably increases when it is used in a pulsed (flashing) mode, because of the continuous need of the visual system to adapt and the annoying nature of the stimulus. In addition, the use of unusual or changing light colors may warn and possibly deter drivers.

The required luminous intensity of a laser for warning drivers can be derived from Figure 13. A luminous intensity of about $60,000 \mathrm{~cd}$ is required in the center of the beam to limit the safe driving speed to about $40 \mathrm{~km} / \mathrm{h}$. The beam width should be large enough to cover the windscreen. Note that narrow beam of the GLOW produces a light spot at $100 \mathrm{~m}$ distance with a diameter of $0.72 \mathrm{~m}$. 


\section{CONCLUSIONS AND RECOMMENDATIONS}

High intensity light sources can in principle be used in low light conditions to give car drivers powerful warning signals or to compromise their ability to perform offensive actions. The objective of the current study was to develop a test protocol for the qualification of high intensity light sources that are intended to be used as warning devices or non-lethal weapons to deny car drivers their view on the outside world through windscreens ${ }^{16}$.

When the beam of a high intensity light source hits a windscreen the driver may experience severe visual contrast reduction due to veiling glare. Veiling glare arises both from light scattered in the eye and light scattered by the windscreen. Dirt and scratches on the windscreen will cause additional light scatter. The visual impact (contrast reduction) of the veiling glare will be most severe at low ambient luminance (night time).

In the current study we measured the scatter function for new and used windscreens that were either clean or dirty. The high intensity light source used in this study was a Green Light Optical Warner (GLOW).We observed no significant difference between the scatter function for new, used and colored windows. The scatter function for dirty windscreens is a factor 14 larger than for clean windscreens.

We also derived a method to assess the possible impact of the illumination of a windscreen by a high intensity light on driving behavior. The method is based on the assumption that drivers will reduce their speed when veiling glare reduces the detection distance of objects on the road. First we calculated the detection distance of an object resembling a rock on the road, for a car using either a driving or passing beam, and for the GLOW in its wide or narrow beam mode. We distinguished between situations where the driver experiences disability glare (i.e., when the light source is in the visual field) and conditions in which the light source is not directly visible. The results show that a device like the GLOW can significantly reduce the detection distance of objects on the road. Disability glare significantly reduces detection distances and yields detection distances that are similar to those obtained with a dirty windscreen and no disability glare.

Next, by adopting the detecting distance as the stopping distance, we calculated the maximum safe driving speed as a function of the luminous intensity of the veiling light source, both for the driving and passing beam of the headlamp and for clean and dirty windshields. The results show that the maximum save driving speed consistently decreases with increasing luminous intensity of the light source.

In future applications, a high intensity light source could be coupled with a laser distance meter and a speedometer ${ }^{1}$. This would allow the operator to assess whether a driver slows down after being engaged by the light source and to assess whether the stopping distance exceeds the distance from the checkpoint to the approaching car. This may help the operator to differentiate between drivers who show an intent to stop and those who are inclined to disregard the stop signal, thus invoking a warranted escalation of force by the operator.

\section{ACKNOWLEDGEMENT}

This study is the result of a co-operative working relationship between the German WTD 52 Centre of Excellence on NLW, WTD 91 on Weapons and Munition, and TNO Defence, Security and Safety.

\section{REFERENCES}

[1] Beer, J., "Laser light stimuli for maritime warning and repulsion: Evolving concepts and capabilities," In: Procedings of the 2010 International Waterside Security Conference (WSS), pp. 1-3, IEEE, Piscataway, NJ, USA, 2010.

[2] Svec, J. and Beer, D., "Directed Energy in the Military Environment," Leading Edge, 7(4) ,pp. 74-77, 2012.

[3] Orbons, S., "Are non-lethal weapons a viable military option to strengthen the hearts and minds approach in Afghanistan?," Defense \& Security Analysis, 28(2) ,pp. 114-130, 2012. 
[4] Smith, P.A., "The transient effects of visible laser light on visual function," In: Laser induced acute visual and cognitive incapacitation of aircrew, protection management, and cockpit integration, pp. 19-24, North Atlantic Treaty Organization, Neuilly-sur-Seine, France, 1996.

[5] McKinlay, A.F. and Harlen, F., "Biological basis of maximum permissible exposure levels of laser standards. I. Damage mechanisms," Journal of the Society of Radiological Protection, 4(1) ,pp. 17-24, 1984.

[6] Randolph, D.L., Schmeisser, E.T. and Beatrice, E.S., "Foveal flashes and human performance," In: Visual protection and enhancement, pp. North Atlantic Treaty Organization, 1985.

[7] SAE. "Safety considerations for high-intensity lights (HIL) directed into the navigable airspace", ARP5560, SAE International, Warrendale, PA, 2008.

[8] American National Standards Institute (2005). American national standard for the safe use of lasers outdoors (Standard Z136.6). New York, USA: The Laser Institute of America.

[9] Arecchi, A.V., Messadi, T. and Koshel, R.J., "Field Guide to Illumination", SPIE Press, Bellingham, WA, 2007.

[10] van den Heuvel, J.C., Toet, A. \& Rieter-Barrell, Y. "Effects of optical devices on humans", TNO-DV 2009 A435, TNO Defense, Security and Safety, The Hague, The Netherlands, 2009.

[11] Allen, M.J., "Windscreen dirt and surface damage effects," The Australian Journal of Optometry, 58(8) ,pp. 180$189,1975$.

[12] Timmerman, A., "Direct measurement of windscreen surface wear and the consequences for road safety," In: A.G. Gale, M.H. Freeman, C.M. Haslegrave, P. Smith \& S.P. Taylor (Ed.), Vision in Vehicles, pp. 331-342, NorthHolland, Amsterdam, NL, 1986.

[13] Adrian, W., "Visibility of targets: model for calculation," Lighting Research \& Technology, 21(4) ,pp. 181-188, 1989.

[14] Blackwell, H.R., "Contrast thresholds of the human eye," Journal of the Optical Society of America, 36(11) ,pp. 624-643, 1946.

[15] CIE. "CIE Equations for disability glare", CIE 146 TC 1-50, International Commission on Illumination CIE, Vienna, Austria, 2002.

[16] Toet, A. \& Alferdinck, J.W.A.M. "Effects of high intensity light sources on vision through windscreens", TNODV 2011 A127, TNO Behavioral and Societal Sciences, Soesterberg, The Netherlands, 2011.

[17] Thales. "GLOW - Green Light Optical Warner", Product Leaflet 04-2010, Belfast, Northern Ireland, 2010.

[18] Technical Comittee CEN/TC 129. "Glass in building - Coated glass - Part 5: Test method and classification for the self-cleaning performances of coated glass surfaces", prEN 1096-5:2009, European Committee for Standardization (CEN), 2009.

[19] Padmos, P. \& Alferdinck, J.W.A.M. "Verblinding bij tunnelingangen - III De invloed van strooilicht van de autovoorruit", IZF 1983 C-10, Instituut voor Zintuigfysiologie TNO, Soesterberg, The Netherlands, 1983.

[20] Padmos, P. and Alferdinck, J.W.A.M., "Straylight from atmosphere and windscreen, related to the surround luminance of tunnel entrances.," In: Proceedings of the 20th Session of the CIE in Amsterdam, pp. International Commission on Illumination CIE, Vienna, Austria, 1983.

[21] Sivak, M., Flannagan, M. and Sato, T., "Light output of U.S., European, and Japanese low-beam headlamps," In: Transportation Research Record No. 1456. Traffic Signing, Signals, and Visibility., pp. 99-111,1994.

[22] ECE. "Uniform provisions concerning the approval of motor vehicle headlamps emmitting an asymetrical passing beam or a driving beam or both and equipped with halogen filament lamps (H4 lamps)", Regulation No. 20 (last revision: 9 September 2001, United Nations, Economic Commission for Europe, Geneva, Swiss, 2001.

[23] American National Standards Institute (2007). American national standard for the safe use of lasers (Standard Z136.1). New York, USA: The Laser Institute of America.

[24] NSVV. "Aanbevelingen verlichting van (korte) tunnels en onderdoorgangen; Kunstlicht voor onderdoorgangen voor snelverkeer en langzaam verkeer", OV-32, Nederlandse Stichting voor Verlichtingskunde, Ede, The Netherlands, 2003.

[25] Hogema, J.H. \& van der Horst, A.R.A. "Driving behaviour in fog: Analysis of inductive loop data", TNO-report TM 1994 C-6, TNO Institute for Human Factors, Soesterberg, The Netherlands, 1994. 